\title{
HORA DO SHOW: UMA APRESENTAÇÃO DO DOSSIÊ TEMÁTICO ARTES NEGRAS
}

\author{
Nelma Cristina Silva Barbosa de Mattos ${ }^{1}$
}

Resumo: Nessa edição, reunimos e divulgamos diferentes olhares investigativos que convergem para as questões raciais, potencializando novas possibilidades de análises e intervenções sobre as desigualdades no campo das artes. O caderno reúne trabalhos de jovens pesquisadores, militantes e artistas de origem negra que propõem questões acerca da criação, da poética, da circulação e da interpretação da obra de arte dessa parcela de artistas historicamente negados e desprestigiados. As pesquisas demonstram que na música, no audiovisual, nas artes visuais, no teatro ou na dança, a identidade negra torna-se elemento emblemático na produção artística contemporânea.

Palavras-chave: artes negras; criação; identidade; cultura afro-brasileira.

\section{SHOWTIME: A PRESENTATION OF THE BLACK ARTS SPECIAL THEMATIC SECTION}

\begin{abstract}
In this edition, we gather and disseminate different investigative perspectives that converge on racial issues, enhancing new possibilities for analysis and interventions on inequalities in the field of the arts. This special thematic section brings together works by young researchers, militants and black artists who propose questions about the creation, poetry, circulation and interpretation of the work of the Black Art. Research shows that in music, audiovisual, visual arts, theater or dance, black identity becomes an emblematic element in contemporary artistic production.
\end{abstract}

Key-words: black arts; creation; identity; afro-brazilian culture.

\section{L'HEURE DU SPECTACLE: PRESENTATION DU DOSSIER THEMATIQUE L'ART DES NOIRES}

Résumé: Dans cette édition, nous rassemblons et diffusons différentes perspectives d'investigation convergeant sur des questions raciales, ouvrant ainsi de nouvelles possibilités d'analyse et d'interventions sur les inégalités dans le domaine des arts. Le magazine rassemble des travaux de jeunes chercheurs, militants et artistes d'origine noire qui proposent des questions sur la création, la poétique, la circulation et l'interprétation de l'œuvre d'art de cette partie d'artistes historiquement négligés et discrédités. Les recherches montrent que dans la musique, le cinema, les arts visuels, le théâtre ou la danse, l'identité noire devient un élément emblématique de la production artistique contemporaine.

Mots-clés: l'art des noires; création; identité; culture afro-brésilienne.

\footnotetext{
${ }^{1}$ Doutora em Estudos Étnicos e Africanos pela UFBA, artista plástica, docente do Instituto Federal de Educação, Ciência e Tecnologia Baiano (IF Baiano) e membro do seu Núcleo de Estudos Afro-brasileiros e Indígenas.E-mail:nelma13@gmail.com
} 


\section{HORA DEL SHOW: UNA PRESENTACIÓN DEL DOSSIER TEMÁTICO DE ARTES NEGRAS}

Resumen: En esta edición, reunimos y difundimos distintas perspectivas de investigación que convergen en temas raciales, potenciando nuevas posibilidades de análisis e intervenciones sobre desigualdades en el campo de las artes. El cuaderno reúne obras de jóvenes investigadores, militantes y artistas de origen negro que proponen preguntas sobre la creación, de la poética, de la circulación y de la interpretación de la obra de arte de esta parte de artistas históricamente negadas y desconsideradas. La investigación muestra que en la música, en el audiovisual, en las artes visuales, en el teatro o en la danza, la identidad negra se convierte en un elemento emblemático de la producción artística contemporánea.

Palabras-clave: artes negras; creación; identidad; cultura afro-brasileña.

A Revista da ABPN é consolidada como um sério espaço de divulgação do conhecimento produzido por pesquisadoras e pesquisadores negros a partir da preocupação com as realidades da população negra. Esse tipo de produção acadêmica afeta a produção de conhecimento, inova seus caminhos e objetivos, colaborando com a promoção de uma cultura de igualdade étnico-racial também no plano da investigação científica e de suas aplicações.

Nessa edição, no Dossiê Temático Artes Negras, reunimos e divulgamos diferentes olhares investigativos que convergem para as questões raciais, potencializando novas possibilidades de análises e intervenções sobre as desigualdades no plano da arte. O caderno reúne trabalhos de jovens pesquisadores, militantes e artistas de origem negra que propõem questões acerca da criação, da poética, da circulação e da interpretação da obra de arte de parcela de artistas historicamente negados e desprestigiados.

Ao longo da tradição de pesquisa em instituições de ensino superior, o negro se tornou o "objeto" de investigação em inúmeras áreas. Mas, foi preterido enquanto "sujeito" criador de conhecimentos, como podemos constatar em nossas diversas áreas de formação. No plano da cultura e das artes não foi diferente. Exaltado pelo potencial criativo de suas manifestações plásticas, musicais ou cênicas, o sujeito negro raras vezes foi reconhecido ou ouvido a respeito da sua produção. Por um lado, a interpretação e a sistematização do conhecimento estético ou artístico desconsidera a presença e a potência intelectual negra, negando-o como autor de reflexões. Por outro, as subjetividades de origem negra despertaram pouco interesse entre os estudiosos da arte ou do negro no Brasil, negando-o como contribuição importante. 
O curioso é que, em se tratando de expressões artísticas, os descendentes de africanos destacaram-se em todas as linguagens. Mas foi preciso ações políticas para que essa contribuição viesse a ser entendida como relevante e potente. Remarcamos que, no século $\mathrm{XX}$, presenciamos o movimento de africanos e seus descendentes pela retomada da África como referencial cultural. Entre as diversas ações, destacamos aquelas protagonizadas por países recém independentes das metrópoles europeias, que foram decisivas para as expressões artísticas e culturais do mundo contemporâneo - e que ainda são capazes de dinamizar mercados da economia criativa do planeta.

Ao tratarmos da arte, interessa-nos enfatizar o fôlego que a temática negra tomou especialmente a partir dos anos 1960 e 1970. Além da emergência de movimentos negros em várias partes do mundo, houve o protagonismo africano na realização de festivais internacionais focados na valorização daquele continente e de seu legado, especialmente no aspecto cultural e artístico.

Para o Brasil, aquela conjuntura favoreceu a capilaridade do trabalho das organizações culturais e políticas que defendiam a melhora da situação da população negra em vários aspectos da sociedade. Houve um pequeno, porém perceptível esforço governamental para aproximação com a África, que estabeleceu marcos como a formação de acervos museológicos de arte tradicional africana e a preocupação em delinear oficialmente um discurso sobre as artes afro-brasileiras. A referência da matriz africana também se destacou a partir de lutas e de trabalhos de artistas como Abdias Nascimento, Emanoel Araújo e outros. É inegável que aquele momento instigou (e ainda instiga) a busca por mais informações de brasileiros sobre a África.

O arcabouço cultural africano espalhado no mundo através dos empreendimentos coloniais, produziu subjetividades diferenciadas, embora com traços semelhantes. Mas, apesar de tantas proximidades com a África e com a evolução no plano das comunicações, ainda sabemos pouco sobre o continente. Absorvemos muitas imagens correspondentes à estereótipos e mantemos lacunas em campos de saberes. Conhecemos poucas narrativas locais.

Por isso, quando a pesquisadora Jusciele Oliveira se debruça sobre o cinema africano de língua portuguesa no artigo ““'O filme será um elemento original da arte negra": sobre os finais metafóricos dos filmes africanos de Flora Gomes”, percebemos uma valiosa imersão no contexto daquele tipo de ficção. A autora, que é formada em Letras pela Universidade Federal da Bahia (UFBA) e doutora em Comunicação, Cultura 
e Artes pela Universidade do Algarve, realiza uma análise original acerca da produção do cineasta bissauense, que segue a tendência contemporânea de uma produção autoral interessada em conceitos, provocações, alteridades, formas próprias, repensando-se enquanto estética, transito e poéticas.

Apesar da densidade do conjunto de obras audiovisuais, consideramos que a produção africana ainda enfrenta a falta de condições de ser divulgada no meio profissional para além de imagens estereotipadas, fundadas em exotismos, inferioridades ou apresentadas sob títulos insuficientes para expressar a complexidade das subjetividades de Áfricas. Contudo, com as tecnologias contemporâneas e a globalização econômica, o referencial africano para a cultura no mundo transformou-se em um agregador de valor a produtos.

$\mathrm{Na}$ música, por exemplo, a internet vem se consolidando como um divulgador essencial da criação e um interessante campo de disputa pela memória. A rede tornouse ferramenta colaborativa de atração e concentração de informações acerca dos artistas, porém a música não conseguiu se desvencilhar de rótulos totalizantes. A descontextualização da criação musical africana na internet, que vem reaproximando-a das representações coloniais das culturas africanas e a luta digital pela salvaguarda da memória daquelas expressões são problematizadas no artigo "Encruzilhadas cyberatlânticas nas rotas de África: música e disputa pela memória na formação de acervos digitais", escrito pelo $D J$, produtor de eventos e historiador Renato de Lyra Lemos. Mestre em Estudos Étnicos e Africanos pela UFBA, ele é doutorando em Antropologia na Universidade Federal de Pernambuco (UFPE).

A disputa pela memória, equidade e afirmação negras também atinge a arte brasileira na atualidade, marcada por movimentos, artistas e intelectuais tocados pelas culturas de origens africanas e suas complexas relações no Brasil. A questão étnicoracial interfere na economia criativa, pois a africanidade vem sendo requisitada nos espaços profissionais de arte. Porém, a discriminação sobrevive em todas as etapas de produção e circulação, estimulando manifestações políticas no plano artístico. Mesmo com a implementação de políticas afirmativas na Educação e Cultura dos últimos vinte anos, não se conseguiu reverter o racismo no meio da arte.

A sensibilidade criativa negra aparece em nossa cultura ora como protagonista (como no caso do samba e outros gêneros musicais), ora como cenário (exemplo das visualidades modernistas, onde são frequentes imagens que retratam costumes e 
aspectos da vida do povo negro-mestiço). Nossos maiores nomes da música, das artes visuais, da dança ou do teatro veiculam-se de alguma forma à herança negra. Ela tem sido a principal fonte de inspiração e oferece sólida base técnica para a performance de diversos sujeitos. Essas referências, entretanto, não foram capazes de garantir igualdade de oportunidade para os profissionais da arte e plena aceitação de processos criativos não-brancos nas agências oficiais da cultura. Os artistas não desfrutam todos da mesma condição de trabalho e prestígio nas instituições.

Desde o centenário da Abolição da Escravatura, as pesquisas envolvendo a produção sensível da população negra são cada vez mais densas. Mas, foi após a Lei 10.639/2003, que a demanda por esses estudos sistematizados aumentou. Isso se reflete no surgimento de grupos de pesquisa e publicações, ao mesmo tempo em que mais artistas-pesquisadores usam sua experiência racial como pano de fundo de processos criativos. Mas, porque é tão importante a enunciação do pertencimento étnico-racial desses sujeitos, uma vez que a arte é a expressão da percepção de mundo? Não bastaria apenas ser "arte"?

Essas e outras perguntas são suscitadas no presente dossiê temático, sem apontar respostas conclusivas, apenas interpretações possíveis através de olhares de sujeitos que percebem a experiência racial negra como território criativo. Nessa edição, notamos como identidade negra torna-se elemento emblemático no campo artístico contemporâneo.

O corpo negro, objeto da exploração colonial, é a síntese de experiências de resistência e reelaborações de si. A força de trabalho da economia colonial se beneficiou de corpos de homens e mulheres. E lhes deixou estigmas, como o na corporeidade feminina negra na dança, o que discute o texto "Corpos moventes em diáspora: dança, identidade e reexistências", da dançarina e professora Dra. Larissa Ferreira, docente do Instituto Federal de Brasília (IFB). Problematizando processos criativos de mulheres negras na área da dança, a autora discorre sobre o poder da criação artística na retomada de si enquanto sujeito no contexto da diáspora.

O pensamento é incrementado com a contribuição de outra dançarina, a professora Ms. Marilza Oliveira (UFBA), no artigo "O tronco histórico da dança afrobrasileira”. Nele, são traçados alguns passos da caminhada de bailarinos negros e bailarinas negras para a institucionalização de uma dança com características estéticas 
afro-brasileiras. A autora toca ainda em um ponto sensível e caro ao artista negro, que é o limite entre a religiosidade de matriz africana e a expressão artística.

O prof. Ms. Tássio Ferreira, da Universidade Federal do Sul da Bahia (UFSB), ator, dramaturgo, diretor teatral e Taata dya Nkisi do Terreiro Unzó ia Kisimbi ria Maza Nzambi (em Simões Filho-Ba) retoma a reflexão entre arte e religião no trabalho "Afrocênica: poéticas de cenas pretas". Essa é uma pesquisa em desenvolvimento no âmbito de seu projeto de doutorado em Artes Cênicas, que tem por referência a pedagogia da circularidade e a ancestralidade. No texto, o artista - sacerdote pesquisador discute algumas estratégias de potencialização da cena teatral contemporânea afrodiásporica, a partir do estudo de alguns grupos teatrais negros.

A performance negra tem na religião de matriz africana um terreno em que é possível a interação com diversas linguagens artísticas. O cotidiano de comunidades tradicionais de terreiro é repleto de instrumentos e potencialidades de expressão poética da fé. Não foi à toa que os estudos sistematizados sobre a arte de origem negra começaram a partir da arte sacra, ainda que tenham sido realizados sob a ótica do racismo.

O fim da discriminação racial, especialmente, no meio artístico, foi a razão da militância do Tata Kinamboji (Arthur Leandro), que era Tata Kisikar'Ngomba ria Nzumbarandá/Mansu Nangetu, artista plástico e docente na Universidade Federal do Pará (UFPA). Falecido em 2018, deixou-nos como um de seus últimos trabalhos o texto "Relatos e experiências sobre Nós, os de Aruanda!" O artigo faz uma minuciosa descrição e análise da experiência de artistas religiosos de matriz africana que, coletivamente, implementaram ações artísticas visando ocupar equipamentos culturais que lhe eram negados no Pará. A proposta desse coletivo é "renegrir" as artes visuais daquele estado.

A narrativa sobre as artes de origem negra no norte do Brasil é reforçada por Claudete Nascimento Machado, artista plástica iniciada em religião de matriz africana e docente da Universidade Federal do Amapá (UNIFAP), e por Patrick Ferreira de Araújo, artista visual e professor da rede pública amapaense. Ambos colaboram com a contextualização da condição do artista visual de terreiro no artigo "Ações e experimentos artísticos na Amazônia amapaense: produção de sujeitos que se autodeclaram "artistas de terreiro"”. No trabalho, é destacada a atuação do Grupo Ewê de Pesquisa em Artes Visuais Contemporâneas, ligado à universidade. 
É interessante observar os espaços institucionais que o grupo tem percorrido para se estabelecer no meio da arte, a importância da universidade para que circulasse sua produção em territórios do centro do sistema artístico brasileiro, como os da cidade de São Paulo. Ainda que seja caudatária das decisões centrais do sistema da arte, isto é, tomadas pela Europa e Estados Unidos, a cidade São Paulo é considerado o lugar mais importante atualmente para as artes da América Latina. De lá, saem as principais orientações e articulações das plataformas expositivas do país e do continente. Não estar lá significa "não estar" no meio profissional da arte.

A artista visual e pesquisadora Janaína Barros Silva Viana, que faz seu pósdoutoramento em Ciência da Informação na Universidade Federal de Minas Gerais (UFMG), contribuiu com o artigo "Para além das fronteiras da arte contemporânea brasileira: epistemologia, arquivo e autoria negra". O texto nos oferece uma perspectiva panorâmica do negro na cena da arte contemporânea de São Paulo ao analisar alguns programas recentes de incentivo à expressão artística de afro-brasileiros. O trabalho apresenta alguns lugares percorridos por jovens artistas negros (paulistas em sua maioria), que resultaram em carreiras de destaque na atualidade.

“Arte Afro-brasileira: contraponto da produção visual no Brasil”, de minha autoria, resulta da tese de doutorado em Estudos Étnicos e Africanos. No artigo, é possível transitar por questões conceituais da arte afro-brasileira, arrematadas pelo processo de institucionalização dessas visualidades. A arte afro-brasileira como campo de estudo é descrita e vista como resistência, assinalando o seu surgimento e contexto contemporâneo, remarcando o pensamento de alguns teóricos e artistas ao longo do século $\mathrm{XX}$, que colaboraram com a consolidação desse tipo de arte no sistema de circulação da produção visual do Brasil. Ao considerar o percurso histórico de resistência da presença negra nas artes plásticas do país, instigamos dúvidas acerca da equidade racial no sistema da arte brasileira.

O "Dossiê Temático Artes Negras" da Revista da ABPN, contudo, não objetiva responder todas as questões inspiradas por análises aqui brevemente apresentadas. Mas, sim, estimular questionamentos acerca de conceitos e atitudes que definem a posição da produção de artistas negro-mestiços no meio profissional da arte e da cultura. Esperamos que essa leitura abra portas para a elaboração de novos estudos sobre o contexto étnico-racial nas expressões artísticas, colaborando com a igualdade de oportunidades para a criação sensível de origem negra. 